\title{
Crystal Engineering: Synthesis and Structural Analysis of Coordination Polymers with Wavelike Properties
}

\author{
Omar W. Steward *, Miles V. Kaltenbach, Ashley B. Biernesser, Matthew J. Taylor, \\ Katie J. Hovan, Jordan J. S. VerPlank, Ameera Haamid, Irina Karpov and Matasebia T. Munie
}

Department of Chemistry and Biochemistry, Bayer School of Natural and Environmental Sciences, 600 Forbes Avenue, Duquesne University, Pittsburgh, PA 15282, USA;

E-Mails: mkaltenb@nd.edu (M.V.K.); biernessera@duq.edu (A.B.B.); matthewjwtaylor@gmail.com (M.J.T.); hovank@duq.edu (K.J.H.); verplan1058@duq.edu (J.J.S.V.); mooka001@sbcglobal.net (A.H.); karpov203@duq.edu (I.K.); mtmunie@stkate.edu (M.T.M.)

* Author to whom correspondence should be addressed; E-Mail: stewardo@duq.edu;

Tel.: +1-412-396-6338; Fax: +1-412-396-5683.

Received: 17 August 2011; in revised form: 5 September 2011 / Accepted: 27 September 2011 / Published: 7 October 2011

\begin{abstract}
Supramolecular coordination polymers with wavelike structures have been synthesized by self-assembly and their structures analyzed using the sine trigonometric function. Slow evaporation of a methylene chloride-methanol solution of a 1:1 molar mixture of $\left[\mathrm{M}(\mathrm{tmhd})_{2}\right]$, where $\mathrm{M}=\mathrm{Co}$ or $\mathrm{Ni}$, and quinoxaline; a 1:2:1 molar mixture of $\left[\mathrm{M}(\mathrm{acac})_{2}\right]$, where $\mathrm{M}=\mathrm{Co}$ or $\mathrm{Ni}, 2,2,6,6$-tetramethyl-3,5-heptadione and quinoxaline; or a 1:2:1 molar mixture of $\left[\mathrm{Co}(\mathrm{acac})_{2}\right]$, dibenzoylmethane, and quinoxaline, yielded the crystalline coordination polymers. In the presence of the nitrogenous base, ligand scrambling occurs yielding the most insoluble product. The synthesis and structures of the following wavelike polymers are reported: trans-[Co(DBM $\left.)_{2}(\mathrm{qox})\right]_{\mathrm{n}} \cdot \mathrm{nH}_{2} \mathrm{O}$ (2), trans $-\left[\mathrm{Co}(\mathrm{tmhd})_{2}(\mathrm{qox})\right]_{\mathrm{n}}(3)$, trans $-\left[\mathrm{Ni}(\mathrm{tmhd})_{2}(\mathrm{qox})\right]_{\mathrm{n}}(\mathbf{4})$, where $\mathrm{DBM}^{-}=$dibenzoylmethanate, $\operatorname{tmhd}^{-}=2,2,6,6$-tetramethyl-3,5-heptadionate, and qox $=$ quinoxaline. The wavelike structures are generated by intramolecular steric interactions and crystal packing forces between the chains. Some of the tert-butyl groups show a two-fold disorder. The sine function, $\varphi=\mathrm{A} \sin 2 \pi \mathrm{x} / \lambda$, where $\varphi=$ distance $(\AA \hat{)})$ along the polymer backbone,

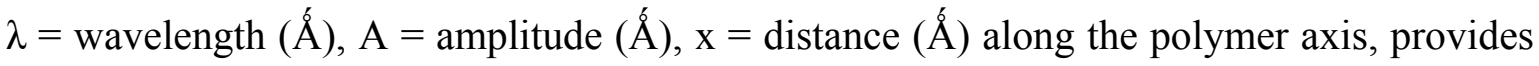
a method to approximate and visualize the polymer structures.
\end{abstract}


Keywords: crystal engineering; wavelike polymers; sine function; wavelength; amplitude; coordination polymers

\section{Introduction}

Molding coordination polymers within the crystal environment to obtain structures of the desired shape is an endeavor which requires the development of synthetic methods using compounds which on reaction produce chains, where the forces directed within and between the polymer chains produce the desired structures. The research is directed toward obtaining coordination polymers with wavelike structural characteristics. In this paper, we have developed self-assembly synthetic procedures which produce crystalline coordination polymeric materials directly from solution by slow evaporation. The starting materials were selected to generate wavelike polymer chains through intramolecular steric interactions within the chain and intermolecular forces, i.e., crystal packing forces, between the chains. The structures of the wavelike polymers were determined by single-crystal X-ray diffraction and the wave characteristics analysed using the sine trigonometric function. Wavelike characteristics of some coordination polymers have been noted previously [1-12]; however, we have been unable to find any references where trigonometric functions were used to analyze the structural data. Recently, a review article has been published on one-dimensional coordination polymers [13].

The synthesis and structures of the following wavelike polymers are reported: trans $-\left[\mathrm{Co}(\mathrm{DBM})_{2}(\mathrm{qox})\right]_{\mathrm{n}} \cdot \mathrm{nH}_{2} \mathrm{O}(\mathbf{2})$, trans $-\left[\mathrm{Co}(\operatorname{tmhd})_{2}(\mathrm{qox})\right]_{\mathrm{n}}(\mathbf{3})$, trans $-\left[\mathrm{Ni}(\mathrm{tmhd})_{2}(\mathrm{qox})\right]_{\mathrm{n}}(\mathbf{4})$, where $\mathrm{DBM}^{-}=$dibenzoylmethanate, $\mathrm{tmhd}^{-}=2,2,6,6$-tetramethyl-3,5-heptadionate, and qox $=$ quinoxaline. $\mathrm{A}$ number of recent studies have reported the synthesis of cobalt(II) and nickel(II) complexes with DBM ${ }^{-}$ and tmhd ${ }^{-}$ligands [14-17]. [Co(tmhd $)_{2}$ ] and [Ni(tmhd) $)_{2}$ are available commercially (see Experimental Section 3.1). A linear polymeric structure of the complex trans-[Co(acac $\left.)_{2}(\mathrm{pz})\right]_{\mathrm{n}}$ has been reported [18]. trans $-\left[\mathrm{Co}(\mathrm{acac})_{2}(\mathrm{qox})\right]_{\mathrm{n}}$, trans $-\left[\mathrm{Ni}(\mathrm{acac})_{2}(\mathrm{qox})\right]_{\mathrm{n}}$, and trans- $\left[\mathrm{Co} / \mathrm{Ni}(\mathrm{acac})_{2}(\mathrm{qox})\right]_{\mathrm{n}}$ are reported to have a zigzag polymeric chain [19].

\section{Results and Discussion}

\subsection{Synthesis of the Polymers}

The coordination polymers were synthesized by self-assembly by mixing the components in a $50 \mathrm{v} / \mathrm{v} \%$ methylene chloride-methanol solution and allowing the most insoluble material, i.e., the polymer, to precipitate or crystallize from solution. Two different mixtures of starting materials were employed: the metal(II) complex, $\beta$-diketone, and dinitrogenous base or the metal(II) $\beta$-diketonate, and dinitrogenous base. In the former, the desired polymeric $\beta$-diketonate which is coordinated to the metal in the polymer chain is added in the keto form, while in the latter, the desired $\beta$-diketonate is added as the metal(II) complex. When quinoxaline is employed as the dinitrogenous base, a slightly basic solution is required for rearrangement and self-assembly to occur. With pyrazine as the dinitrogenous base, the coordination polymer precipitates from solution on mixing solutions of the starting components; whereas, with quinoxaline, crystals of the coordination polymer form on slow 
evaporation of the solvent. Therefore, a slow mixing procedure was adopted to grow crystals of trans $-\left[\mathrm{Co}(\mathrm{DBM})_{2}(\mathrm{pz})\right]_{\mathrm{n}}(\mathbf{1})$. A solution of the metal complex, $\left[\mathrm{Co}(\mathrm{ac})_{2}\right] \cdot 4 \mathrm{H}_{2} \mathrm{O}$, in methanol and a solution of dibenzoylmethane and pyrazine in methylene chloride were slowly allowed to mix on diffusion through a glass filter as described in the Experimental Section 3.2.2.

\subsection{Structures of the Polymers}

The structures of four coordination polymers are reported, and the crystallographic data for these polymers are listed in Table 1. The CCDC numbers for the four structures are listed in the Experimental Section 3.5. All of the complexes form one-dimensional polymer chains; however, one polymer is linear whereas the other three have wavelike characteristics.

Table 1. Crystallographic data collection and refinement results for structures 1-4.

\begin{tabular}{lllll}
\hline & \multicolumn{1}{c}{$\mathbf{1}$} & \multicolumn{2}{c}{$\mathbf{2}$} & \multicolumn{1}{c}{$\mathbf{3}$} \\
\hline formula & $\mathrm{C}_{34} \mathrm{H}_{26} \mathrm{CoN}_{2} \mathrm{O}_{4}$ & $\mathrm{C}_{76} \mathrm{H}_{60} \mathrm{Co}_{2} \mathrm{~N}_{4} \mathrm{O}_{10}$ & $\mathrm{C}_{90} \mathrm{H}_{132} \mathrm{Co}_{3} \mathrm{~N}_{6} \mathrm{O}_{12}$ & $\mathrm{C}_{90} \mathrm{H}_{132} \mathrm{Ni}_{3} \mathrm{~N}_{6} \mathrm{O}_{12}$ \\
formula weight & 585.50 & $1,307.93$ & $1,666.81$ & $1,666.15$ \\
temperature $(\mathrm{K})$ & $296(2)$ & $110(2)$ & $296(2)$ & $296(2)$ \\
crystal system & monoclinic & triclinic & orthorhombic & orthorhombic \\
space group & $\mathrm{C} 2 / \mathrm{c}$ & $\mathrm{P} \overline{1}$ & Pccn & Pccn \\
$a(\AA)$ & $20.752(3)$ & $14.7059(3)$ & $40.1388(4)$ & $39.458(4)$ \\
$b(\AA)$ & $7.2117(10)$ & $15.0161(3)$ & $12.82360(10)$ & $12.8326(19)$ \\
$c(\AA)$ & $19.973(3)$ & $15.8680(3)$ & $20.1409(2)$ & $20.136(2)$ \\
$\alpha(\operatorname{deg})$ & 90.0 & $111.0740(10)$ & 90.0 & 90.0 \\
$\beta(\operatorname{deg})$ & $93.486(2)$ & $93.8310(10)$ & 90.0 & 90.0 \\
$\gamma(\mathrm{deg})$ & 90.0 & $99.7510(10)$ & 90.0 & 90.0 \\
$\mathrm{~V}\left(\AA^{3}\right)$ & $2983.7(7)$ & $3191.23(11)$ & $10369.19(17)$ & $10195.9(19)$ \\
$\mathrm{Z}$ & 4 & 2 & 4 & 4 \\
$\rho_{\text {calcd. }}\left(\mathrm{Mg} / \mathrm{m}^{-3}\right)$ & 1.303 & 1.356 & 1.068 & 1.085 \\
$R 1[I>2 \sigma(I)]$ & 0.0494 & 0.0481 & 0.0563 & 0.0426 \\
$w R 2[I>2 \sigma(I)]$ & 0.1388 & 0.1325 & 0.1607 & 0.1286 \\
\hline
\end{tabular}

Pyrazine, a dinitrogenous base, produces linear polymer structures with cobalt(II) with both acac and $\mathrm{DBM}^{-}$ligands: trans- $\left[\mathrm{Co}(\mathrm{acac})_{2}(\mathrm{pz})\right]_{\mathrm{n}}$ [17] and trans- $\left[\mathrm{Co}(\mathrm{DBM})_{2}(\mathrm{pz})\right]_{\mathrm{n}}(\mathbf{1})$. The polymeric structure of $\mathbf{1}$ is shown in Figure 1. The structure of $\mathbf{1}$ differs from the structure of trans $-\left[\mathrm{Co}(\mathrm{acac})_{2}(\mathrm{pz})\right]_{\mathrm{n}}$ in that the crystal packing is different, $\mathrm{C} 2 / \mathrm{c} v s . \mathrm{P} \overline{1}$, and there are no centers of symmetry along the polymer chain of 1 . These cobalt(II) complexes exhibit long Co-N bonds, 2.203-2.227 $\AA$, as a result of Jahn-Teller distortion.

When the dinitrogenous base quinoxaline, is employed, the resulting polymer is no longer linear as a result of the asymmetrical intramolecular and interchain forces. When the $\beta$-diketonate is acac ${ }^{-}$a zigzag chain structure is observed for trans-[Co(acac) $\left.)_{2}(\mathrm{qox})\right]_{\mathrm{n}}[19]$; however, when the $\beta$-diketonate is $\mathrm{DBM}^{-}$, a wavelike chain structure is observed for trans $-\left[\mathrm{Co}(\mathrm{DBM})_{2}(\mathrm{qox})\right]_{\mathrm{n}} \cdot \mathrm{nH}_{2} \mathrm{O}$ (2), see Figures 2 and 3. The X-ray data for 2 was collected at $110 \mathrm{~K}$ to enhance the structural refinement. The spatial requirements of the phenyl groups in the $\mathrm{DBM}^{-}$ligands compared to the methyl groups in the acac 
ligands may result in the differences in the chain structures The Co-N bonds, $2.250-2.285 \AA$, are slightly longer in the quinoxaline complexes as compared to the pyrazine complexes. The structure of 2 contains disordered interstitial water molecules of 0.5 occupancies; the hydrogen atoms on the water molecules were not located.

Figure 1. Ball-and-stick model of trans-[Co(DBM $\left.)_{2}(\mathrm{pz})\right]_{\mathrm{n}}(\mathbf{1})$ showing a portion of the polymer chain. The hydrogen atoms are not included for clarity $(\mathrm{C}$, gray; $\mathrm{Co}$, blue; $\mathrm{N}$, purple; O, red).

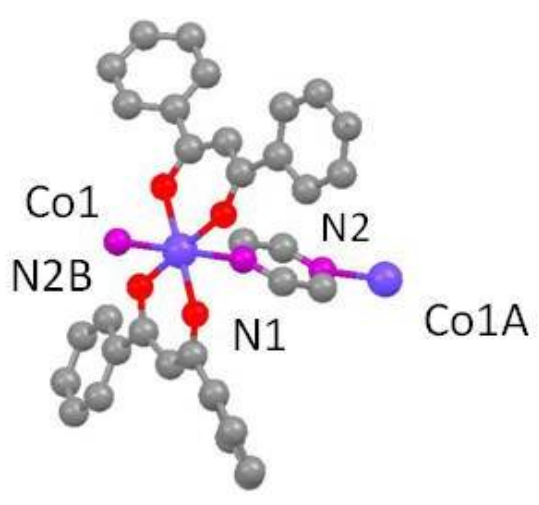

Figure 2. Ball-and-stick model of trans $-\left[\mathrm{Co}(\mathrm{DBM})_{2}(\mathrm{qox})\right]_{\mathrm{n}} \cdot \mathrm{nH}_{2} \mathrm{O}$ (2), showing the asymmetric unit. $\mathrm{Co} 1$ and $\mathrm{Co} 3$ are located at $i$ symmetry positions, i.e., nodes, on the wavelike polymer chain. The disordered interstitial water molecules have occupancies of 0.5 . The hydrogen atoms are not included for clarity ( $\mathrm{C}$, gray; $\mathrm{Co}$, blue; N, purple; $\mathrm{O}$, red).

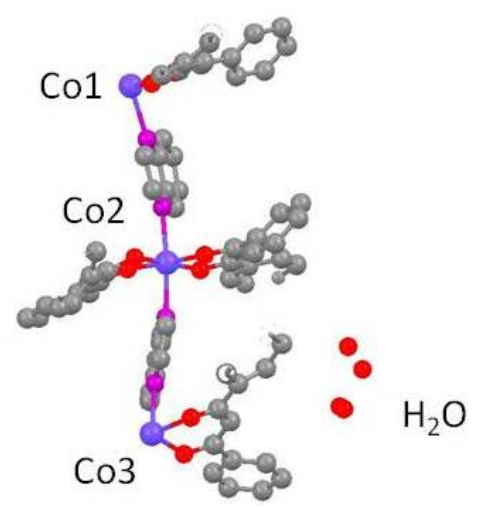

Figure 3. Ball-and-stick model of a portion of the wavelike chain of 2 showing the repeating arrangement of $\mathrm{Co}$ atoms in the chain. The hydrogen atoms are not included for clarity (C, gray; Co, blue; N, purple; $\mathrm{O}$, red).

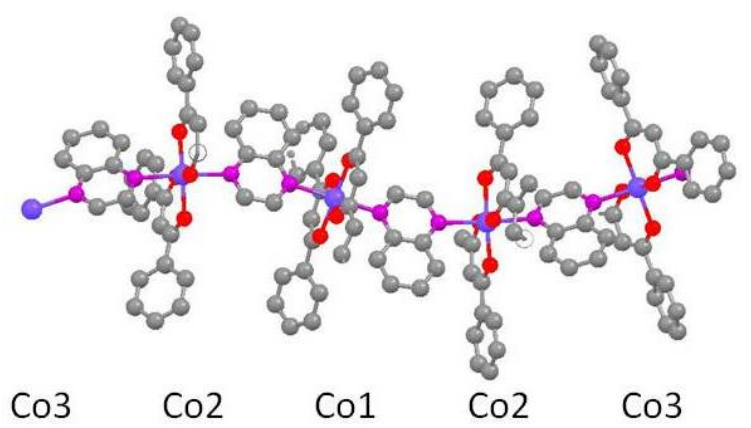


Both of the coordination polymer chains in trans-[Co(tmhd $)_{2}($ qox $\left.)\right]_{\mathrm{n}}(3)$ and trans $-\left[\mathrm{Ni}(\mathrm{tmhd})_{2}(\mathrm{qox})\right]_{\mathrm{n}}$ (4) also exhibit wavelike characteristics, see Figures 4-7. The Co-N bond lengths, 2.201-2.223 $\AA$ in 3 are similar to the distances reported above for the cobalt(II)-pyrazine complexes. In the nickel(II) complex, 4, the Ni-N bonds, $2.173 \AA$, are shorter than the Co-N bonds in 3.

Figure 4. Ball-and-stick model of trans-[Co(tmhd $\left.)_{2}(\mathrm{qox})\right]_{\mathrm{n}}(3)$, showing the asymmetric unit. A plane of symmetry bisects a quinoxaline molecule on Co1, and an $i$ symmetry element lies on Co2. The C80 tert-butyl group shows a two-fold disorder. The hydrogen atoms are not included for clarity $(\mathrm{C}$, gray; $\mathrm{Co}$, blue; $\mathrm{N}$, purple; $\mathrm{O}$, red).



Figure 5. Ball-and-stick model showing a portion of the wavelike polymer chain of trans $-\left[\mathrm{Co}(\mathrm{tmhd})_{2}(\mathrm{qox})\right]_{\mathrm{n}}(\mathbf{3})$. The hydrogen atoms are not included for clarity $(\mathrm{C}$, gray; Co, blue; N, purple; $\mathrm{O}$, red).

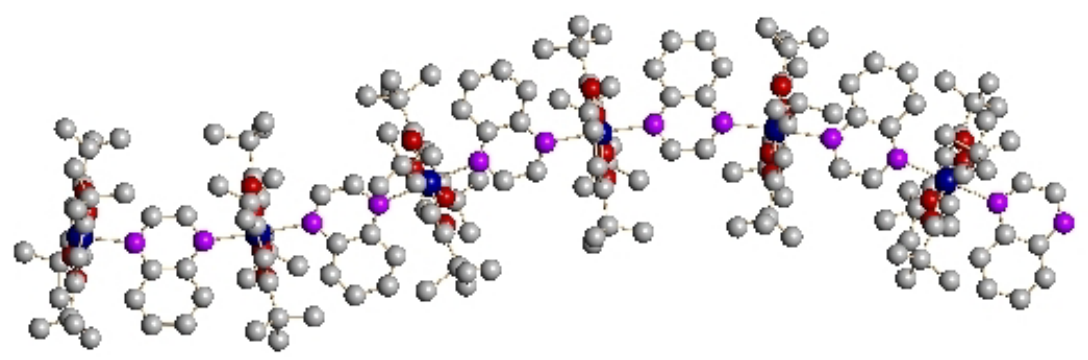

Figure 6. Ball-and-stick model of trans-[Ni(tmhd $\left.)_{2}(\mathrm{qox})\right]_{\mathrm{n}}(4)$, showing the asymmetric unit. A plane of symmetry bisects a quinoxaline molecule on Ni1 and an $i$ symmetry element lies on Ni2. All but one tert-butyl groups, designated by the central carbon atoms, show two-fold disorder, see Table 2. The hydrogen atoms are not included for clarity (C, gray; $\mathrm{Ni}$, green; $\mathrm{N}$, purple; $\mathrm{O}$, red).

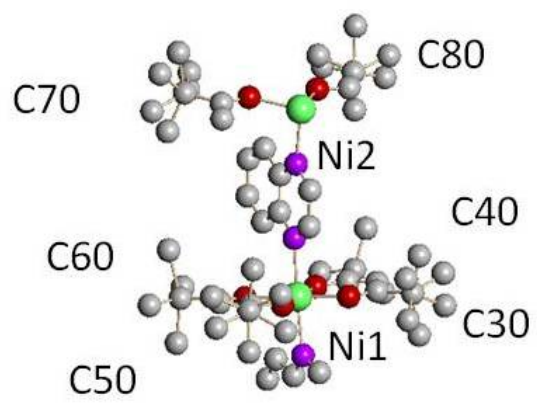


Figure 7. Ball-and-stick model showing a portion of the wavelike polymer chain of trans-[Ni(tmhd $\left.)_{2}(\mathrm{qox})\right]_{\mathrm{n}}(4)$. The hydrogen atoms are not included for clarity $(\mathrm{C}$, gray; $\mathrm{Ni}$, green; $\mathrm{N}$, purple; $\mathrm{O}$, red).

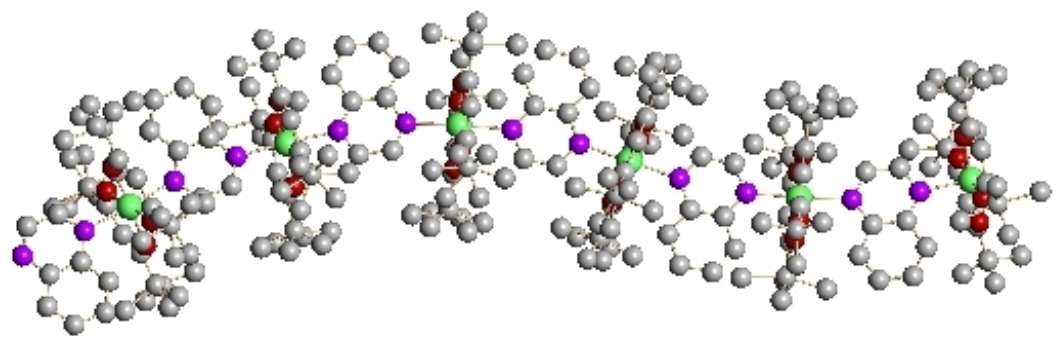

Some of the tert-butyl groups in $\mathbf{3}$ and $\mathbf{4}$ show a two-fold disorder. The tert-butyl groups are designated by the numbers of the central carbon atoms (see Figures 4 and 6). All other atoms in a tert-butyl group have the same number in the ten digits. In $\mathbf{3}$, only one of the tert-butyl groups, C80, in the asymmetric unit shows significant disorder, major position $56 \%$, minor position $44 \%$ (see Figure 4). In 4, five of the six tert-butyl groups in the asymmetric unit show significant two-fold disorder (see Figure 6 and Table 2). A separate variable was used to model the disorder of each group.

Table 2. Extent of the two-fold disorder of the tert-butyl groups in trans-[Ni(tmhd $\left.)_{2}(\mathrm{qox})\right]_{\mathrm{n}}$.

\begin{tabular}{ccc}
\hline tert-Butyl Group & Major Position \% & Minor Position \% \\
\hline C30 & 100 & 0 \\
C40 & 57 & 43 \\
C50 & 52 & 48 \\
C60 & 62 & 38 \\
C70 & 58 & 42 \\
C80 & 67 & 33 \\
\hline
\end{tabular}

\subsection{Structural Analysis and Trigonometric Functions}

When analyzing the structures of wavelike polymers, trigonometric functions are useful since they introduce the variables of wavelength and amplitude which aid in visualizing the characteristics of the polymer chain. We have used the sine function, $\varphi=\mathrm{A} \sin 2 \pi \mathrm{x} / \lambda$, where $\varphi=$ distance $(\AA)$ along the polymer backbone, $\lambda$ = wavelength $(\AA), \mathrm{A}=$ amplitude $(\AA), \mathrm{x}=$ distance $(\AA)$ along the polymer axis, to determine these variables for the coordination polymers $\mathbf{2}, \mathbf{3}$, and $\mathbf{4}$ described in Section 2.2. The wavelength, repeating units per wavelength and amplitude for these polymers are given in Table 3.

Table 3. Wavelengths, amplitudes, and repeating units per wavelength for the polymer chains.

\begin{tabular}{lccc}
\hline \multicolumn{1}{c}{ Polymer } & $\boldsymbol{\lambda} /(\AA)$ & $\mathbf{A} /(\AA)$ est. & Polymer Units $\boldsymbol{\lambda}$ \\
\hline trans $-\left[\mathrm{Co}(\mathrm{DBM})_{2}(\mathrm{qox})\right]_{\mathrm{n}} \cdot \mathrm{nH}_{2} \mathrm{O}(\mathbf{2})$, & 28.66 & 1.7 & 4 \\
trans $-\left[\mathrm{Co}(\mathrm{tmhd})_{2}(\mathrm{qox})\right]_{\mathrm{n}}(\mathbf{3})$ & 42.12 & 2.4 & 6 \\
trans $-\left[\mathrm{Ni}(\mathrm{tmhd})_{2}(\mathrm{qox})\right]_{\mathrm{n}}(\mathbf{4})$ & 41.48 & 2.7 & 6 \\
\hline
\end{tabular}

Polymer 2 crystallizes in the triclinic space group, $\mathrm{P} \overline{1}$, which allows only $i$ symmetry elements. The polymer chain is constructed from the asymmetric unit shown in Figure 2 to form the chain pictured in 
Figure 3 with each wave node occurring at a special position, i.e., a center of symmetry, which lies on $\mathrm{Co} 1$ and Co3. Each center of symmetry in Figure 2 represents one-half of a cobalt atom yielding two cobalt atoms per asymmetric unit. Two asymmetric units represent one polymer wavelength which contains four cobalt atoms. The amplitude of the wave, which cannot be calculated directly from the data, was estimated graphically.

Polymers 3 and $\mathbf{4}$ crystallize in the orthorhombic space group Pccn, with the polymer chains lying along the $a$ axes. The asymmetric unit in each case has a center of symmetry at one end and a horizontal plane of symmetry, perpendicular to the $a$ axis, at the other end, see Figures 4 and 6 . Again, each wave node represents a center of symmetry, i.e., $\mathrm{Co} 2$ or Ni2, and a horizontal plane of symmetry bisects one of the quinoxaline ligands bonded to Col or Nil. Reflection of the asymmetric unit in the mirror plane doubles the number of metal centers to three producing centers of symmetry at each end of the larger unit. Inversion of this unit through a center of symmetry generates one wavelength consisting of six metal centers.

\section{Experimental Section}

\subsection{Starting Materials}

The solvents, methanol and methylene chloride, were obtained from commercial sources and used without further purification. The sources of the chemicals are as indicated: cobalt(II) acetylacetonate $\left(\left[\mathrm{Co}(\mathrm{acac})_{2}\right]\right)$ and dibenzoylmethane $(\mathrm{DBMH})$ from TCI America; cobalt(II) acetate 4-hydrate ([Co(ac $\left.\left.)_{2}\right] \cdot 4 \mathrm{H}_{2} \mathrm{O}\right)$, nickel(II) bis(2,2,6,6-tetramethyl-3,5-heptanedionate) ([Ni(tmhd) $\left.\left.)_{2}\right]\right), 2,2,6,6$-tetramethyl3,5-heptanedione (tmhdH), and pyrazine (pz) from Aldrich; nickel(II) acetylacetonate ([Ni(acac) $\left.)_{2}\right)$, quinoxaline (qox), and cobalt(II) bis(2,2,6,6-tetramethyl-3,5-heptanedionate) ([Co(tmhd) $\left.)_{2}\right]$ ) from Alfa Aesar.

\subsection{Syntheses and Crystallization Procedures}

\subsection{1. trans- $\left[\mathrm{Co}(\mathrm{DBM})_{2}(\mathrm{pz})\right]_{\mathrm{n}}(\mathbf{1})$ Powder}

$\left[\mathrm{Co}(\mathrm{ac})_{2}\right] \cdot 4 \mathrm{H}_{2} \mathrm{O}, 0.25 \mathrm{~g}(1.00 \mathrm{mmol})$, was dissolved in $25 \mathrm{~mL}$ of methanol by heating on a steam bath yielding a magenta solution. DBMH, $0.45 \mathrm{~g}(2.00 \mathrm{mmol})$ and pyrazine, $0.08 \mathrm{~g}(1.00 \mathrm{mmol})$, were dissolved in $25 \mathrm{~mL}$ of methylene chloride by heating on a steam bath resulting in a light orange solution. On mixing the above solutions, an orange precipitate formed. The precipitate was filtered and allowed to air dry. The orange powder 1, $0.45 \mathrm{~g}$, represents a $76 \%$ yield. Anal. Calcd. for $\mathrm{C}_{34} \mathrm{H}_{26} \mathrm{CoN}_{2} \mathrm{O}_{4}$ : C, 69.74; H, 4.47\%. Found: C, 69.43; H, 4.74\%.

\subsection{2. trans $-\left[\mathrm{Co}(\mathrm{DBM})_{2}(\mathrm{pz})\right]_{\mathrm{n}}(\mathbf{1})$ Crystals}

$\left[\mathrm{Co}(\mathrm{ac})_{2}\right] \cdot 4 \mathrm{H}_{2} \mathrm{O}, 0.25 \mathrm{~g}(1.00 \mathrm{mmol})$, was dissolved in $25 \mathrm{~mL}$ of methanol by heating on a steam bath yielding a magenta solution. DBMH, $0.45 \mathrm{~g}$ (2.00 mmol), and pyrazine, $0.08 \mathrm{~g}$ (1.00 mmol), were dissolved in $25 \mathrm{~mL}$ of methylene chloride by heating on a steam bath resulting in a light orange solution. The methanol solution was placed in a filter crucible, $30 \mathrm{~mL}-30 \mathrm{M}$, in a $150 \mathrm{~mL}$ beaker, and the methylene chloride solution was placed in the beaker. The levels were adjusted by adding solvent. 
A bent, open-ended melting point tube was inserted under the filter crucible to allow the air to vent. The beaker was then placed in a closed glass jar. After 11 days, red crystals of 1, $0.44 \mathrm{~g}$, a $75 \%$ yield, formed, in the bottom of the beaker. IR $\left(\mathrm{cm}^{-1}\right): 3,056 \mathrm{vw}, 2,170 \mathrm{vw}, 1,590 \mathrm{~s}, 1,544 \mathrm{~s}, 1,516 \mathrm{~m}, 1,480 \mathrm{~m}$, $1,453 \mathrm{~m}, 1,402 \mathrm{~s}, 1,303 \mathrm{vw}, 1,228 \mathrm{~m}, 1,179 \mathrm{w}, 1,153 \mathrm{w}, 1127 \mathrm{w}, 1070 \mathrm{w}, 1024 \mathrm{~m}, 939 \mathrm{~m}, 854 \mathrm{vw}$, $809 \mathrm{sh}, 763 \mathrm{~m}, 725 \mathrm{~s}, 700 \mathrm{~s}, 621 \mathrm{~s}, 533 \mathrm{~m}$.

\subsection{3. $\operatorname{trans}-\left[\mathrm{Co}(\mathrm{DBM})_{2}(\mathrm{qox})\right]_{\mathrm{n}} \cdot \mathrm{nH}_{2} \mathrm{O}(\mathbf{2})$}

[Co(acac $)_{2}$ ], $0.43 \mathrm{~g}(1.67 \mathrm{mmol})$, was dissolved in $25 \mathrm{~mL}$ of methylene chloride by heating on a steam bath yielding a dark red solution. On addition of $0.75 \mathrm{~g}(3.34 \mathrm{mmol})$ of DBMH, the solution turned orange and a precipitate formed. Quinoxaline, $0.43 \mathrm{~g}(3.34 \mathrm{mmol})$, dissolved in $25 \mathrm{~mL}$ of methanol was added to the solution. On addition, the precipitate dissolved and the color changed to a dark red. This solution was allowed to slowly evaporate. After five days, red crystals had formed. After filtering and air drying, $0.70 \mathrm{~g}$ of crystals of 2 was obtained, a 73\% yield. Anal. Calcd. for $\mathrm{C}_{38} \mathrm{H}_{60} \mathrm{CoN}_{2} \mathrm{O}_{5} ; \mathrm{C}, 69.78 ; \mathrm{H}, 4.62 \%$. Found: $\mathrm{C}, 69.42 ; \mathrm{H}, 4.79 \%$. IR $\left(\mathrm{cm}^{-1}\right): 3,059 \mathrm{w}, 1,748 \mathrm{w}, 1,592 \mathrm{~m}$, $1,542 \mathrm{~s}, 1,516 \mathrm{~m}, 1,476 \mathrm{~s}, 1,455 \mathrm{w}, 1,402 \mathrm{w}, 1,307 \mathrm{w}, 1,287 \mathrm{w}, 1,225 \mathrm{w}, 1,179 \mathrm{w}, 1,157 \mathrm{~m}, 1,145 \mathrm{~m}$, $1,047 \mathrm{~s}, 1,023 \mathrm{~m}, 1,000 \mathrm{~s}, 962 \mathrm{~m}, 937 \mathrm{~m}, 867 \mathrm{~m}, 808 \mathrm{~m}, 784 \mathrm{~s}, 757 \mathrm{~m}, 717 \mathrm{~m}, 683 \mathrm{~m}, 623 \mathrm{~s}, 528 \mathrm{~m}$, $452 \mathrm{~m}$.

\subsection{4. trans $\left[\mathrm{Co}(\mathrm{tmhd})_{2}(\mathrm{qox})\right]_{\mathrm{n}}(3)$}

[Co(tmhd $)_{2}$ ], $0.21 \mathrm{~g}(0.68 \mathrm{mmol})$, was dissolved in $25 \mathrm{~mL}$ of methylene chloride yielding a red solution. On addition of $0.09 \mathrm{~g}(0.68 \mathrm{mmol})$ of quinoxaline, dissolved in $25 \mathrm{~mL}$ of methanol, the solution turned orange. The solution was allowed to slowly evaporate. After 12 days, red crystals had formed in the bottom of the flask. After filtering and air drying, $0.11 \mathrm{~g}$ of crystals of $\mathbf{3}$ was obtained, a $29 \%$ yield. Anal. Calcd. for $\mathrm{C}_{30} \mathrm{H}_{44} \mathrm{CoN}_{2} \mathrm{O}_{4}: \mathrm{C}, 64.85 ; \mathrm{H}, 7.98 \%$. Found: C, 64.68; H, 7.82\%. IR $\left(\mathrm{cm}^{-1}\right): 3,059 \mathrm{w}, 1,748 \mathrm{w}, 1,592 \mathrm{~m}, 1,542 \mathrm{~s}, 1,516 \mathrm{~m}, 1,476 \mathrm{~s}, 1,455 \mathrm{w}, 1,402 \mathrm{w}, 1,307 \mathrm{w}, 1,287 \mathrm{w}$, $1,225 \mathrm{w}, 1,179 \mathrm{w}, 1,157 \mathrm{~m}, 1,145 \mathrm{~m}, 1,047 \mathrm{~s}, 1,023 \mathrm{~m}, 1,000 \mathrm{~s}, 963 \mathrm{~m}, 937 \mathrm{~m}, 867 \mathrm{~m}, 808 \mathrm{~m}, 784 \mathrm{~s}$, $757 \mathrm{~m}, 717 \mathrm{~m}, 683 \mathrm{~m}, 623 \mathrm{~s}, 528 \mathrm{~m}, 452 \mathrm{~m}$.

Crystals of polymer 3 also can be prepared by the slow evaporation of a $50 \mathrm{v} / \mathrm{v} \%$ methylene chloride-methanol solution of a 1:2:1 molar mixture of $\left[\mathrm{Co}(\mathrm{acac})_{2}\right], \mathrm{tmhdH}$, and quinoxaline.

\subsection{5. trans-[Ni(tmhd $)_{2}($ qox $\left.)\right]_{\mathrm{n}}(4)$}

[Ni(tmhd $\left.)_{2}\right], 0.43 \mathrm{~g}(1.01 \mathrm{mmol})$, was dissolved in $25 \mathrm{~mL}$ of methylene chloride yielding a pale green solution. On addition of $0.09 \mathrm{~g}(0.68 \mathrm{mmol})$ of quinoxaline, dissolved in $25 \mathrm{~mL}$ of methanol, the solution turned bright green. The solution was allowed to slowly evaporate. After 8 days, green crystals had formed in the bottom of the flask. After filtering and air drying, $0.26 \mathrm{~g}$ of crystals of 4 was obtained, a $69 \%$ yield. Anal. Calcd. for $\mathrm{C}_{30} \mathrm{H}_{44} \mathrm{~N}_{2} \mathrm{NiO}_{4}$ : C, 64.85; H, 7.98\%. Found: C, 64.68; $\mathrm{H}, 7.82 \%$. IR $\left(\mathrm{cm}^{-1}\right): 2,959 \mathrm{w}, 2,864 \mathrm{w}, 1,570 \mathrm{~m}, 1,504 \mathrm{~m}, 1,488 \mathrm{~m}, 1,359 \mathrm{~m}, 1,286 \mathrm{w}, 1,246 \mathrm{~m}$, $1,219 \mathrm{~m}, 1,183 \mathrm{~s}, 1,138 \mathrm{~s}, 1,054 \mathrm{w}, 1,021 \mathrm{w}, 967 \mathrm{~m}, 935 \mathrm{w}, 823 \mathrm{~m}, 743 \mathrm{~s}, 617$ w, $484 \mathrm{~m}$. 
Crystals of polymer 4 also can be prepared by the slow evaporation of a $50 \mathrm{v} / \mathrm{v} \%$ methylene chloride-methanol solution of a 1:2:1 molar mixture of [ $\left.\mathrm{Ni}(\mathrm{acac})_{2}\right], \mathrm{tmhdH}$, and quinoxaline.

\subsection{Elemental Analyses}

Elemental Analyses were performed by H. Malissa and G. Reuter GmbH at the Analytische Laboratorien, Industriepark Kaiserau, (Haus Heidbruch), D-51789 Lindlar, Germany.

\subsection{Measurements}

Infrared spectra were determined on a NEXUS 470 FT-IR or a Perkin Elmer Spectrum 100 FT-IR.

\subsection{Structure Determination}

Crystals of 1-4 were selected for structure determinations by X-ray diffraction procedures. Data collections were obtained on a Bruker Smart Apex-II CCD diffractometer using graphite-monochromic MoK $\alpha$ radiation $(\lambda=0.71073 \AA)$. Collection of full data sets using $\phi$ and $\omega$ scan modes were carried out over the $2 \theta$ range of $2-58^{\circ}$. Data were collected at ambient temperature (296 K) except for 2 which was collected at $110 \mathrm{~K}$. The structure 1 was solved by the Patterson method and structures 2, 3, and 4 by the direct method (SHELXS-97). The structures were refined by the full-matrix least squares method (SHELXL-97). Non-hydrogen atoms were refined anisotropically and hydrogen atoms were located and refined isotropically. In 2 , the hydrogen atoms on the disordered water molecules with 0.5 occupancies were not located. The data on crystals 1-4 are listed in Table 1. Additional structural data in CIF format is available from the Cambridge Structural Database; see CCDC reference numbers 828910-828914.

\section{Conclusions}

Through crystal engineering, crystalline coordination polymers with chains possessing wavelike characteristics have been synthesized by self-assembly by slow evaporation of a $50 \mathrm{v} / \mathrm{v} \%$ methylene chloride-methanol solution containing a metal(II) complex, a $\beta$-diketone, and a dinitrogenous base or a metal(II) $\beta$-diketonate and a dinitrogenous base, where the metal is cobalt or nickel. The wavelike characteristics of the polymer chains are produced by controlling the intra- and inter-chain steric forces.

Trigonometric functions are important tools for analyzing and visualizing the structures of the crystalline polymers where the repeating units resemble a waveform. As demonstrated above, the sine function is useful in analyzing the structures of polymer chains which have the characteristics of a sine wave. This analysis aids in the understanding of how the polymer chains are constructed from the asymmetric units. By combining trigonometric functions one would expect that more complex structures with repeating polymer units which resemble waveforms could be quantified and better visualized. 


\section{Acknowledgments}

Sincere appreciation to the Camille and Henry Dreyfus Senior Scientist Mentoring Program, the National Science Foundation (CRIF 0234872 and REU CHE-0354052), Jennifer Aitken, and the Instrument Shop (Dan Bodner, Dave Hardesty, and Lance Crosby) for their assistance.

\section{References}

1. Liang, Y.; Liu, M.; Zhang, N.; Wang, Q.; Niu, Y.; Liu, X.; Hou, H. Synthesis and structure of a $\mathrm{CdI}_{2}$ coordination polymer with 1,1'-(1,4-butanediyl)bis-1H-benzotriazole(bbbt). J. Chem. Crystallogr. 2011, 41, 617-620.

2. Wang, H.; Zhang, L.-F.; Ni, Z.-H.; Zhong, W.-F.; Tian, L.-J.; Jiang, J. Synthesis, crystal structures, and magnetic properties of one-dimensional mixed cyanide- and phenolate-bridged heterotrimetallic complexes. Cryst. Growth Des. 2010, 10, 4321-4324.

3. Qin, L.; Wang, F.; Zhao, Z.-G.; Zhang, Q.-S.; Lu, C.-Z. Synthesis, structure, and luminescence of a 1-D chain of copper(I) cyanide decorated by triphenylphosphine. Chin. J. Struct. Chem. 2010, 29, 270-274.

4. Xu, C.; Wu, F.-H.; Duan, T.; Zhang, Q.-F. One dimensional coordination polymers of cadmium thiolates with 4,4'-trimethylenebipyradine ligands. Z. Naturforsch. 2009, 64b, 805-808.

5. Fang, M.-J.; Li, M.-X.; He, X.; Shao, M.; Pang, W.; Zhu, S.-R. Synthesis, structure and thermal stability of ternary metal complexes based on polycarboxylate and N-heterocyclic ligands. J. Mol. Struct. 2009, 921, 137-143.

6. Li, X.-M.; Niu, Y.-L.; Wang, Q.-W.; Liu, B. Poly[[aqua(2,2-bipyridyl)( $\mu_{3}-$ pyridine-3,4dicarboxylato)manganese(II)] monohydrate]. Acta Crystallogr. 2007, E6, m1737-m1738.

7. Mantero, D.G.; Neels, A.; Stoeckli-Evans, H. Novel 3D, 2D, and 0D first-row coordination compounds with 4,4'-bipyridine-N,N'-dioxide incorporating sulfur-containing anions. Inorg. Chem. 2006, 45, 3287-3294.

8. Qin, S.; Ke, Y.; Lu, S.; Li, J.; Pei, H.; Wu, X.; Du, W. Synthesis and structure characterization of three-coordinate silver(I) and seven-coordinate cobalt(II) coordination polymers with 4-pyridylthioacetate. J. Mol. Struct. 2004, 689, 78-80.

9. Zhang, H.T.; Shao, T.; Wang, H.Q.; You, X.Z. A one-dimensional double-wavelike chain coordination polymer: Catena-poly[[diaquamanganese(II)]- $\mu-\left(2,2^{\prime}\right.$-bipyridyl-3,3'-dicarboxylato$\left.\left.\kappa^{4} \mathrm{~N}^{\mathrm{N}} \mathrm{N}^{\prime}: \mathrm{O}, \mathrm{O}^{\prime}\right)\right]$. Acta Crystallogr. 2003, E59, m342-m344.

10. Niu, Y.; Hou, H.; Zhu, Y. Self-assembly of $\mathrm{d}^{10}$ metal adduct polymers bridged by bipyridyl-based ligands. J. Cluster Chem. 2003, 14, 483-493.

11. Muthu, S.; Yip, J.H.K.; Vittal, J.J. Coordination polymers of $\mathrm{d}^{10}$ metals and N,N'-bis(3pyridinecarboxamide)-1,2-ethane. J. Chem. Soc. Dalton Trans. 2001, 3577-3584.

12. Irwin, M.J.; Vittal, J.J.; Yap, G.P.A.; Puddephatt, R.J. Linear gold(I) coordination polymers: A polymer with a unique sine wave configuration. J. Am. Chem. Soc. 1996, 116, 13101-13102.

13. Leong, W.L.; Vittal, J.J. One-dimensional coordination polymers: Complexity and diversity in structures, properties, and applications. Chem. Rev. 2011, 111, 688-764. 
14. Becker, G.; Niemeyer, M.; Mundt, O.; Schwarz, W.; Westerhausen, M.; Ossberger, M.W.; Mayer, P.; Noeth, H.; Zhong, Z,; Dijkstra, P.J.; Feijen, J. Crystal structures and spectroscopic properties of $2 \lambda^{3}$-phospha-1,3-dionates and 1,3-dionates of calcium. Comparative studies on the 1,3-diphenyl and 1,3-di(tert-butyl) derivatives. Z. Anorg. Allg. Chem. 2004, 630, 2605-2621.

15. Soldatov, D.V.; Henegouwen, A.T.; Enright, G.D.; Ratcliffe, C.I.; Ripmeester, J.A. Nickel(II) and zinc(II) dibenzoylmethanates: Molecular and crystal structure, polymorphism, and guest- or temperature-induced oligomerization. Inorg. Chem. 2001, 40, 1626-1636.

16. Soldatov, D.V.; Ripmeester, J.A. Novel 4-vinylpyridine-extended metal-dibenzoylmethanate host frameworks: Structure, polymorphism, and inclusion properties. Chem. Eur. J. 2001, 7, 2979-2994.

17. Caneschi, A.; Cornia, A.; Fabretti, A.C.; Gatteschi, D. Structure and magnetic properties of a dodecanuclear twisted-ring iron(III) cluster. Angew. Chem. Int. Ed. 1999, 38, 1295-1297.

18. Ma, B.-Q.; Gao, S.; Yi, T.; Xu, G.-X. One-dimensional coordination polymers $\left[\mathrm{Co}(\mathrm{acac})_{2} \mathrm{pz}\right]_{\mathrm{n}}$ and $\left[\mathrm{Co}(\mathrm{acac})_{2}\left(4,4^{\prime} \text {-bipy }\right)\right]_{\mathrm{n}}\left(\mathrm{acac}=\right.$ acetylacetone, $\mathrm{pz}=$ pyrazine, bipy $=4,4^{\prime}$-bipyridine $)$ : Synthesis, structures and magnetic properties. Polyhedron 2001, 20, 1255-1261.

19. Steward, O.W.; Waheed, A.; Chang, S.-C.; Nakashima, M.; Tokii, T. Cobalt(II) and Nickel(II) acetylacetonate-quinoxaline polymers. In Book of Abstracts, Proceedings of 2000 International Chemistry Conference of Pacific Basin Nations, Honolulu, HA, USA, 14-19 December 2000; INOR 49.

(C) 2011 by the authors; licensee MDPI, Basel, Switzerland. This article is an open access article distributed under the terms and conditions of the Creative Commons Attribution license (http://creativecommons.org/licenses/by/3.0/). 